\title{
Immunohistochemical Analysis of Inflammatory Cells in Benign and Precancerous Lesions and Carcinoma of the Prostate
}

\author{
Tomomi Fujii $^{a}$ Keiji Shimada ${ }^{a}$ Osamu Asai ${ }^{c}$ Nobumichi Tanaka ${ }^{b}$ \\ Kiyohide Fujimoto $^{b}$ Kazuya Hirao $^{d}$ Noboru Konishi $^{a}$ \\ Departments of a Pathology and ${ }^{b}$ Urology, Nara Medical University School of Medicine, ${ }^{C}$ Department of \\ Internal Medicine, Uda Municipal Hospital, and ${ }^{\mathrm{d}}$ Department of Urology, Hirao Hospital, Nara, Japan
}

\section{Key Words}

Prostatitis · Prostate carcinoma - Lymphocytes •

Macrophages $\cdot \mathrm{CD} 68 \cdot \mathrm{CD} 204$

\begin{abstract}
Objective: Inflammation is an important cause of tumorigenesis in various types of malignancy. Mediators derived from inflammatory cells are associated with cancer proliferation, angiogenesis, and DNA damage. In the present study, we immunohistochemically examined the infiltration patterns of inflammatory cells in benign glands including glandular hyperplasia, and in prostatic intraepithelial neoplasia and adenocarcinoma. Methods: Formalin-fixed, paraffinembedded tissues were obtained from 100 patients with prostate cancer. All patients underwent radical prostatectomy. We assessed the number of infiltrating $T$ cells $\left(C D 3^{+}\right), B$ cells $\left(\mathrm{CD} 20^{+}, \mathrm{CD} 79\right.$ alpha $\left.{ }^{+}\right)$, and macrophages $\left(\mathrm{CD}^{\circ} 8^{+}, \mathrm{CD} 204^{+}\right)$ in benign and malignant prostate tumors. Results: $\mathrm{CD}^{+} 8^{+}$ macrophages infiltrated benign glands to a higher extent than those of adenocarcinoma. In contrast, the number of $\mathrm{CD} 204^{+}$cells was higher in malignant glands than in benign glands. There was no significant difference in the number of infiltrating $T$ cells between benign and malignant tumors; however, the number of infiltrating B cells was significantly
\end{abstract}

reduced in malignant glands. Conclusions: Inflammation of the prostate may act on prostate carcinomas; particularly that involving M2 macrophage infiltration may play a significant role in prostate carcinogenesis.

Copyright $\odot 2013$ S. Karger AG, Basel

\section{Introduction}

Chronic prostatitis is diagnosed using needle biopsy, transurethral resection, or radical prostatectomy specimens. Epidemiological studies of prostatic carcinoma show significant associations between infection and cancer. Inflammatory stress causes repeated genomic damage leading to transformation, vascularization, apoptosis, and DNA mutation. During bacterial infection, inflammatory cells such as lymphocytes, neutrophils, and macrophages frequently infiltrate into or around the tumor foci. This results in the production of reactive oxygen and nitrogen species, and various cytokines leading to the destruction of the environmental microcosm. In addition to bactericidal effects, these free radicals degrade proteins and damage tissues, resulting in irreversible DNA damage and malignant transformation. Inflammatory cells secrete a number of cytokines and chemokines that

\section{KARGER}

Fax +4161306 1234

E-Mail karger@karger.ch

www.karger.com
C) 2013 S. Karger AG, Basel

$1015-2008 / 13 / 0803-0119 \$ 38.00 / 0$

Accessible online at:

www.karger.com/pat
Dr. Noboru Konishi, PhD

Department of Pathology, Nara Medical University School of Medicine 840 Shijo-cho, Kashihara, Nara 634-8521 (Japan)

E-Mail nkonishi@naramed-u.ac.jp 
Table 1. Characteristics of prostatic cancer for immunohistochemistry

\begin{tabular}{ll}
\hline Cases, $\mathrm{n}$ & 100 \\
Benign gland & 81 \\
Normal & 55 \\
Glandular hyperplasia & 26 \\
PIN & 25 \\
Adenocarcinoma & 68 \\
Age (range), years & $67.3(52-77)$ \\
PSA (range), ng/ml & $11.8(3.9-139)$ \\
Gleason score, $\mathrm{n}$ & \\
$\leq 6$ & 16 \\
7 & 71 \\
$\geq 8$ & 13 \\
\hline
\end{tabular}

promote the outgrowth of neoplastic cells, in addition to autocrine growth factor production by the tumor cells [1]. Reactive free radical overload and some types of cytokines have been recognized as important risk factors for tumorigenesis $[1,2]$. The release of such mediators induces the interaction of inflammatory cells with tumor cells resulting in the simultaneous advance of tumor growth and the extension of inflammation. On the other hand, other proteins or cytokines have been associated with tumor suppression or antitumorigenesis. For example, we isolated a highly expressed protein that we originally designated as prostate cancer antigen-1 (PCA-1), which repairs methylmethane sulfonate-induced alkylation damage in human cells [3].

In the prostate, normal glands, glandular hyperplasia, and adenocarcinoma are often accompanied by inflammation to some extent. Although the infiltration of inflammatory cells might be associated with the proliferation of glandular cells, eventually leading to cancer development, it remains unclear what types of inflammatory cells infiltrate and how these cells affect benign and malignant glandular cells.

Several reports have indicated an important role for infiltrative monocyte chemotactic protein-1 (MCPs) in cancer development and stated that tumor-associated macrophage (TAM) infiltration was found to be closely correlated with poor outcomes in several types of human malignancies [4-7]. In lung cancer, pancreatic cancer, and glioma, $\mathrm{CD} 204^{+}$macrophages infiltrate around the tumor and contribute to progression. Macrophages are divided into 2 types according to their function: a tumorsuppressive (M1) function and a tumor-supportive (M2) function [8]. M2 macrophages play important roles in tu- morigenesis, angiogenesis, matrix remodeling, and metastasis $[9,10]$.

In the present study, we examined the composition of the inflammatory infiltrate in malignant and benign foci using radical prostatectomy specimens from patients with glandular hyperplasia, prostatic intraepithelial neoplasia (PIN), and adenocarcinoma.

\section{Materials and Methods}

\section{Patients}

A total of 100 patients with prostate cancer underwent radical prostatectomy at the Nara Medical University Hospital. All patients signed an institutional review board-approved informed consent form. The clinicopathologic data used in this study were reviewed by 2 urological pathologists (K.S. and N.K., Department of Pathology, Nara Medical University Hospital) and are summarized in table 1.

Histopathological Studies and Evaluation of Inflammation

All surgical specimens were fixed with $10 \%$ formalin and embedded in paraffin. Prostate sections $(3-4 \mu \mathrm{m})$ were stained with hematoxylin and eosin (HE) stain. Three observers (T.F., O.A., and N.K.) evaluated the histological type: benign glands, glandular hyperplasia, PIN, and adenocarcinoma, and samples containing leukocytes surrounding glands were selected. Inflammatory grade was determined according to a classification proposed as mild: individual inflammatory cells, most of which are separated by distinct intervening spaces; moderate: confluent sheets of inflammatory cells with no tissue destruction or lymphoid nodule/ follicle formation, or severe: confluent sheets of inflammatory cells with tissue destruction or lymphoid nodule/follicle formation [11].

\section{Immunohistochemistry}

After reviewing the HE-stained slides of selected specimens, we followed the same tissue fixation and processing procedure as described in previous reports [12-14]. The slides were deparaffinized in xylene, dehydrated in a graded ethanol series, and subsequently rinsed with distilled water. Antigen retrieval methods and the final dilution of antibodies for immunohistochemistry are indicated in table 2 . Three pathologists (T.F., O.A., and N.K.) counted CD20 ${ }^{+}, \mathrm{CD}_{79} \mathrm{alpha}^{+}, \mathrm{CD}^{+}, \mathrm{CD} 4, \mathrm{CD} 8, \mathrm{CD}^{+} 8^{+}, \mathrm{CD} 204^{+}$, and CD163 cells in a high-power microscopic field $(\times 400 ; 0.00625$ $\left.\mathrm{mm}^{2}\right)$.

\section{Statistical Analysis}

We diagnosed prostate glands according to histopathological findings as benign, glandular hyperplasia, PIN, or adenocarcinoma with inflammation, and classified the grading of inflammation as mild, moderate, or severe. The significance of the association of inflammation between benign, glandular hyperplasia or PIN, and adenocarcinoma was assessed using Student's t test (Prizm4; GraphPad Software, Inc.). p $<0.05$ was considered statistically significant. 
Table 2. Immunohistochemical analysis of the prostatic tissue

\begin{tabular}{lllll}
\hline Antigen & Antibody clone & Dilution & Antigen retrieval method & Source \\
\hline CD3 & PS1 & Prediluted & Autoclave & Nichirei, Japan \\
CD4 & 1F6 & $1: 40$ & Autoclave & Leica, Germany \\
CD8 & C8/144B & Prediluted & Autoclave & DAKO, Denmark \\
CD20 & L-26 & Prediluted & - & Nichirei, Japan \\
CD79 $\alpha$ & HM57 & Prediluted & Autoclave & Nichirei, Japan \\
CD68 & Kp-1 & $1: 100$ & Protease & DAKO, Denmark \\
CD204 & SRA-C6 & $1: 100$ & Autoclave & Cosmo Bio, Japan \\
CD163 & 10D6 & $1: 100$ & Autoclave & Leica, Germany \\
\hline
\end{tabular}

\section{Results}

\section{Grade of Inflammatory Cell Infiltration in Benign} and Precancerous Lesions and Adenocarcinoma of the Prostate

In order to examine whether the grade of inflammatory cell infiltration is associated with the histological pattern, the grade of the inflammatory cell was classified as mild, moderate, or severe, according to the grading system described previously in Materials and Methods (fig. 1a). The number of inflammatory cells within benign glands including glandular hyperplasia was much higher than that in PIN or adenocarcinoma (fig. 1b). The grade of inflammation was not significantly different among the Gleason patterns (fig. 1c). In a past report, no significant difference was found between mild and severe inflammation when considering patient age, preoperative serum prostate-specific antigen (PSA), Gleason score, or the percentage of organ-confined disease [15]. Thus, our result revealed that inflammatory cells contribute to cancer progression, but they are not involved in the differentiation of prostate cancer.

\section{Identification of Leukocyte Types in Benign and Cancerous Glands of the Prostate}

Immunohistochemical results of leukocyte distribution around the benign glands, PIN, and adenocarcinoma are shown in figure 2 . The inflammatory cells present consisted of $\mathrm{CD}^{+} \mathrm{T}$ cells, CD20/CD79alpha ${ }^{+} \mathrm{B}$ cells, and macrophages, in both the benign and the malignant glands. However, plasma cells, neutrophils, and eosinophils were rare. It is evident that $\mathrm{CD}^{+} \mathrm{T}$ and $\mathrm{CD} 20$ / $\mathrm{CD}$ 79alpha ${ }^{+} \mathrm{B}$ lymphocytes predominantly infiltrated the benign glands including glandular hyperplasia, PIN, and adenocarcinoma.

Inflammatory Cell Infiltration in the Prostate
Theyer et al. [16] previously indicated that the kinds of lymphocytes infiltrating the prostate were composed of approximately $70 \%$ T cells, $15 \%$ B cells, and $15 \%$ macrophages. In our results, the frequency of $B$ cells in benign glands was 59\%; interestingly, the ratio of infiltrating B cells was significantly reduced in both PIN and adenocarcinoma (PIN: 29\%, adenocarcinoma: 31\%). The rate of $\mathrm{CD}^{+} \mathrm{T}$ cells was not significantly different among benign glands, PIN, and adenocarcinoma (fig. 3a). Similarly, the rate of $\mathrm{CD}^{+}$and $\mathrm{CD}^{+}{ }^{+} \mathrm{T}$ cells was not significantly different among these glands, but the rate of $\mathrm{CD} 8^{+} \mathrm{T}$ cells was lower than that of $\mathrm{CD} 4^{+} \mathrm{T}$ cells in each gland (fig. $3 \mathrm{~b}$ ).

\section{Infiltration of $\mathrm{CD} 8^{+} / \mathrm{CD} 204^{+}$Macrophages Was}

Higher in Cancerous Glands of the Prostate

Recent studies indicated that $\mathrm{CD}^{+} 8^{+}, \mathrm{CD}_{163}{ }^{+}$, or CD204 ${ }^{+}$macrophages were observed with significantly high expression in borderline and malignant tumors, such as prostate cancer, glioma, and pancreatic cancer, and were associated with the grade of histological malignancy and a poor prognosis $[4,5,17]$. We examined the involvement of M2 macrophages in inflammation in benign glands, PIN, and adenocarcinoma of the prostate. The relationships between infiltrating $\mathrm{CD}^{+} 8^{+}$and $\mathrm{CD} 204^{+}$macrophages are shown in figure 4 . The infiltration of $\mathrm{CD} 68^{+}$macrophages was higher in benign glands compared with PIN and adenocarcinoma. In contrast, CD204 ${ }^{+}$cells were more abundant in PIN and adenocarcinoma when compared with benign glands. Consequently, the $\mathrm{CD} 204^{+}: \mathrm{CD}^{+} 8^{+}$ratio was increased in PIN and adenocarcinoma. Identification of $\mathrm{CD}^{+} 8^{+}$using the pan macrophage marker indicated that these cells infiltrated into benign glands, PIN, and adenocarinomas to the same extent (fig. 4b). These data indicate that infiltration of CD204 $4^{+}$macrophages correlated with the early step of carcinogenesis of the prostate (fig. 4).

Pathobiology 2013;80:119-126 


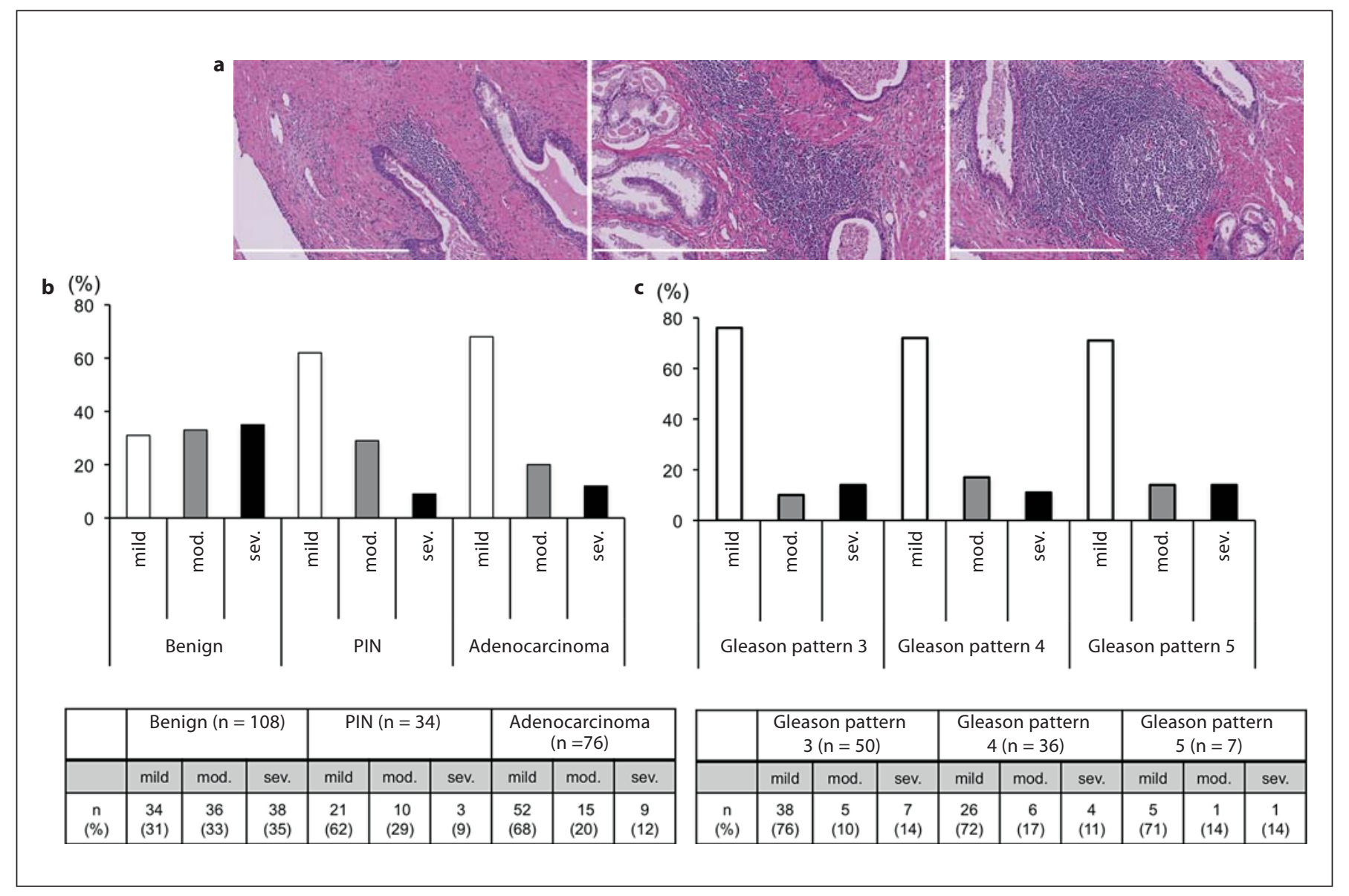

Fig. 1. Grade of inflammation in different types of prostate tissue (a). The grade of inflammation was classified as follows: mild, individual inflammatory cells, most of which are separated by distinct intervening spaces; moderate, confluent sheets of inflammatory cells with no tissue destruction or lymphoid nodule/fol- licle formation, and severe, confluent sheets of inflammatory cells with tissue destruction or lymphoid nodule/follicle formation. (b, c) The percentage of mild, moderate, and severe inflammation in benign, PIN, and adenocarcinoma (b), or each Gleason patterns $(\mathbf{c})$. mod. $=$ Moderate; sev. $=$ severe.

\section{Prostatic Inflammation and Serum PSA}

In our study, 98 patients exhibited high serum PSA values $(>4 \mathrm{ng} / \mathrm{ml})$ at the initial diagnosis, but there was no significant difference in PSA values among patients with severe, moderate, or mild inflammation (data not shown).

\section{Discussion}

In the present study, we indicate for the first time that different types of inflammatory cells infiltrate the tissue during prostatitis in malignant glands compared to those found in benign glands or precancerous lesions. Macrophages are immune-response cells that surround cancer- ous tissue to affect the immune response of the host. Previous studies have indicated that TAM infiltration functions as an adverse prognostic factor in certain tumors, such as glioma, and lung and pancreatic cancer $[4,5,7]$. Several cytokines associated with TAM recruitment and differentiation have been reported. M2 macrophages are $\mathrm{CD}^{2} 4^{+}$cells and are associated with tumorigenesis, angiogenesis, and matrix remodeling $[4,10,17,18]$. CD204 ${ }^{+}$ cells contribute to several factors involved in local infiltration including lymphovascular invasion. Thus, $\mathrm{CD} 204^{+}$macrophages contribute to the local invasion by cancer cells.

The $\mathrm{CD} 68^{+}$macrophage is known as a pan-monocyte/ macrophage marker; however, all of the TAMs are not positive for $\mathrm{CD} 68$. $\mathrm{CD}^{+} 8^{+}$macrophages reportedly in- 


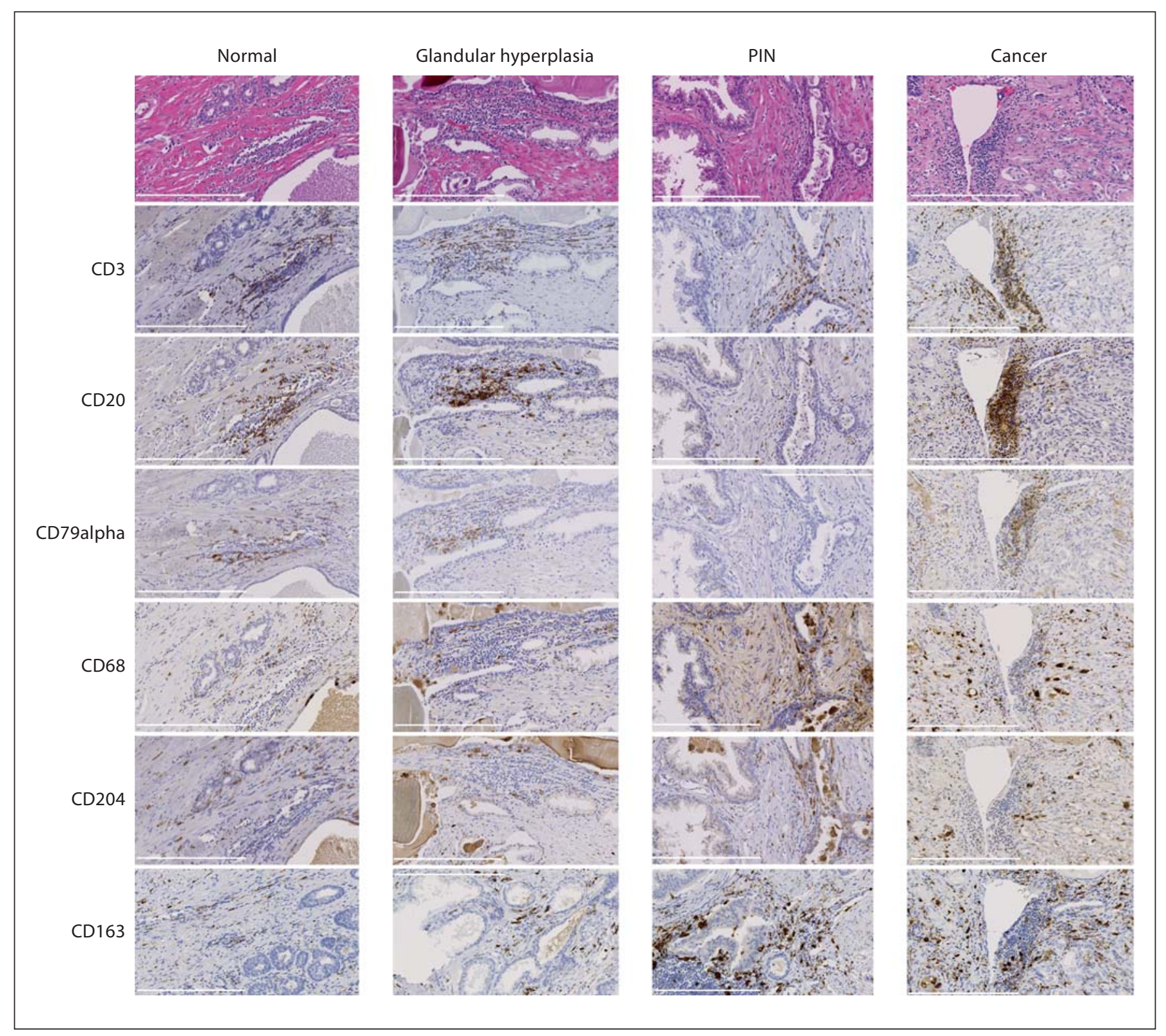

Fig. 2. Immunohistochemical staining of infiltrated inflammatory cells in prostate glands. The normal glands with severe inflammation, glandular hyperplasia with moderate inflammation, PIN with mild inflammation, and adenocarcinoma with mild inflammation were immunostained for CD3, CD20, CD79alpha, CD68, CD204, and CD163. The DAB staining represents a positive reaction.

filtrate esophageal squamous carcinoma [6]. Moreover, in bladder cancer, infiltration of $\mathrm{CD}^{+} 8^{+}$macrophages was higher in muscular invasive tumors than in noninvasive and superficial invasive phenotypes [19].

Our results indicated that the infiltration of $\mathrm{CD}^{+} 8^{+}$ macrophages was high in benign glands but reduced in PIN and adenocarcinoma. In contrast, CD204 ${ }^{+}$cells were more abundant in PIN and adenocarcinoma when compared to benign glands. Consequently, the CD204 ${ }^{+} /$ $\mathrm{CD}^{+} 8^{+}$ratio was increased in PIN and adenocarcinoma. We therefore suggest that the presence of $\mathrm{CD} 204^{+}$macrophages indicates a tumor-progressive phenotype; however, we cannot suggest that the increase in CD20 $4^{+}$cells results in tumor formation as the increase in number 
Fig. 3. Immunohistochemical detection of T-cell and B-cell (a), or CD4 and CD8 (b) infiltration in benign and malignant prostate. Positive cells were counted in the high-power field. The bars represent the percentage of positive cells from the number of infiltrating cells in 200 cells.
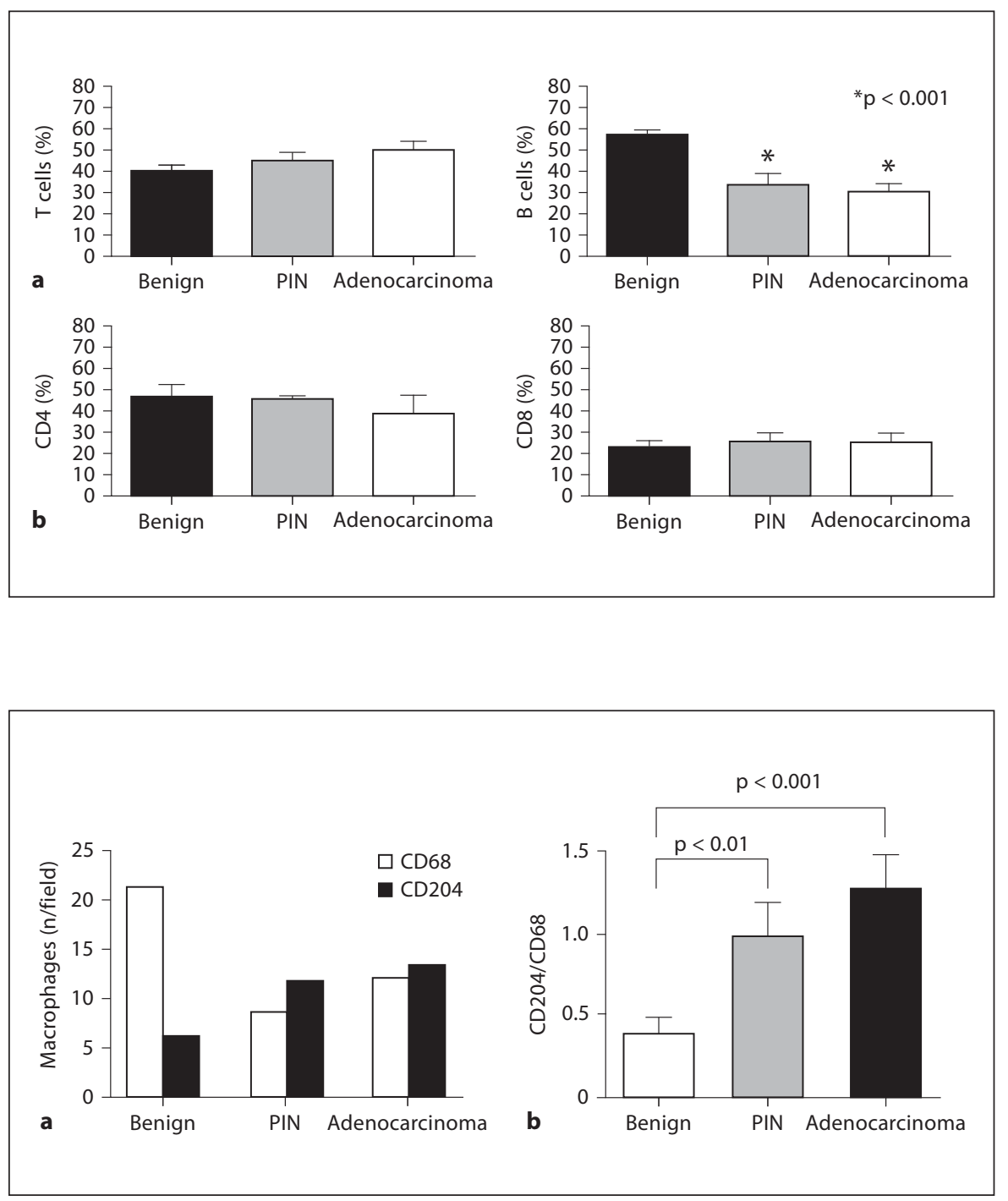

Fig. 4. CD68 and CD204 infiltration in benign and malignant prostate. Immunohistochemical detection of $\mathrm{CD}^{+} 8^{+}$and CD204 ${ }^{+}$cells; positive cells were counted in the high-power field. Among the benign glands, PIN, and adenocarcinoma, the infiltrating macrophages correlated significantly with CD204/CD68. may be a mechanism to prevent further tumor progression. Recent reports indicated that CD204 was capable of attenuating immunostimulatory adjuvant-induced antitumor immunity [20]. Thus, the CD204+ macrophage may function as a tumor suppressor; however, conflicting data regarding this have been accumulated. Therefore, the manner in which CD20 $4^{+}$macrophages influence prostate carcinogenesis and cancer progression should be further examined. Although $\mathrm{CD} 68^{+}$macrophages are pan-monocyte/macrophage markers, not all of the M2 macrophages are necessarily positive for CD68. The number of CD204 ${ }^{+}$cells is slightly higher than that of $\mathrm{CD} 8^{+}$cells. $\mathrm{CD} 204^{+}$cells that are not macrophages may also occur.
Previous studies indicated that asymptomatic chronic prostatitis is observed in $68-100 \%$ of patients, and inflammatory cells of the prostate are found to be entirely composed of T lymphocytes (70-80\%) in needle biopsy, transurethral resection, or radical prostatectomy specimens $[16,21-25]$. In the present study, no statistical difference in the number of infiltrating T cells was observed between the benign and malignant glands. Interestingly, B cells comprised $57 \%$ of infiltrating cells in benign glands; this number was significantly reduced in malignant glands. Inflammatory cytokines including $\mathrm{TNF} \alpha$, IL-6, and IL-8 play an important role in oncogenesis and tumor progression, whereas other kinds of cytokines including IL-17E have antitumour activity [26-29]. Thus, B cells contribute to both tumor progression and suppres- 
sion. The prostate is frequently exposed to bacterial/viral infection, and the T cell/B cell-mediated immune system functions as a defense mechanism. Th1 and Th2 are induced by IL-12 and PGE2 secreted from antigen-presenting cells, respectively. Th1 cells contribute to cell-mediated immunity, whereas Th2 cells mediate humoral immunity. We speculate that the Th1/Th2 balance determines whether T cells or B cells will function as the predominant immune modulator in chronic prostatitis. Unlike in Western populations, the Th2-dependent B-cell elimination of extrinsic organisms may be involved in chronic inflammation of the prostate in Japanese patients. As the sustained Th2 predominant status leads to tumorigenesis of various types of organs including the prostate, we should consider that B-cell-rich inflammation may be associated with a rapid increase in the num- ber of patients with prostate cancer in Japan. In contrast to chronic prostatitis, $\mathrm{T}$ cells predominantly infiltrate in or around prostate adenocarcinomas, as observed in our current study. This result indicates that cell-mediated immunity primarily acts in response to the invasion of prostate cancer cells.

In conclusion, the current study indicated that CD204 ${ }^{+}$ macrophages surrounding cancerous glands could be a marker for tumor-related macrophages. Inflammation of the prostate, particularly that involving infiltrating M2 macrophages, is essential for the progression of the tumor. Therefore, a more accurate insight into the role of $\mathrm{CD} 204^{+}$macrophages and consideration of the microenvironment in the cancerous gland of the prostate has important implications for prostate carcinogenesis and cancer progression.

\section{References}

$\checkmark 1$ Federico A, Morgillo F, Tuccillo C, Ciardiello F, Loguercio C: Chronic inflammation and oxidative stress in human carcinogenesis. Int J Cancer 2007;121:2381-2386.

- Lu H, Ouyang W, Huang C: Inflammation, a key event in cancer development. Mol Cancer Res 2006;4:221-233.

-3 Konishi N, Nakamura M, Ishida E, Shimada $\mathrm{K}$, Mitsui E, Yoshikawa R, Yamamoto H, Tsujikawa K: High expression of a new marker PCA-1 in human prostate carcinoma. Clin Cancer Res 2005;11:5090-5097.

-4 Komohara Y, Ohnishi K, Kuratsu J, Takeya $\mathrm{M}$ : Possible involvement of the M2 antiinflammatory macrophage phenotype in growth of human gliomas. J Pathol 2008;216: $15-24$.

5 Kurahara H, Shinchi H, Mataki Y, Maemura K, Noma H, Kubo F, Sakoda M, Ueno S, Natsugoe S, Takao S: Significance of M2polarized tumor-associated macrophage in pancreatic cancer. J Surg Res 2011;167:e211e219.

-6 Liu J, Li Z, Cui J, Xu G, Cui G: Cellular changes in the tumor microenvironment of human esophageal squamous cell carcinomas. Tumour Biol 2012;33:495-505.

7 Ohtaki Y, Ishii G, Nagai K, Ashimine S, Kuwata T, Hishida T, Nishimura M, Yoshida J, Takeyoshi I, Ochiai A: Stromal macrophage expressing CD204 is associated with tumor aggressiveness in lung adenocarcinoma. J Thorac Oncol 2010;5:1507-1515.

8 Bingle L, Brown NJ, Lewis CE: The role of tumour-associated macrophages in tumour progression: implications for new anticancer therapies. J Pathol 2002;196:254-265.
\$9 Buddingh EP, Kuijjer ML, Duim RA, Bürger $\mathrm{H}$, Agelopoulos K, Myklebost O, Serra M, Mertens F, Hogendoorn PC, Lankester AC, Cleton-Jansen AM: Tumor-infiltrating macrophages are associated with metastasis suppression in high-grade osteosarcoma: a rationale for treatment with macrophage activating agents. Clin Cancer Res 2011;17: 2110-2119.

10 Qian BZ, Pollard JW: Macrophage diversity enhances tumor progression and metastasis. Cell 2010;141:39-51.

-11 Nickel JC, True LD, Krieger JN, Berger RE, Boag AH, Young ID: Consensus development of a histopathological classification system for chronic prostatic inflammation. BJU Int 2001;87:797-805.

12 Konishi N, Nakamura M, Kishi M, Nishimine M, Ishida E, Shimada K: Heterogeneous methylation and deletion patterns of the INK4a/ARF locus within prostate carcinomas. Am J Pathol 2002;160:1207-1214.

-13 Shimada K, Matsuyoshi S, Nakamura M, Ishida E, Konishi N: Phosphorylation status of Fas-associated death domain-containing protein (FADD) is associated with prostate cancer progression. J Pathol 2005;206:423432.

14 Shimada K, Nakamura M, Ishida E, Higuchi T, Tanaka M, Ota I, Konishi N: c-Jun NH2 terminal kinase activation and decreased expression of mitogen-activated protein kinase phosphatase-1 play important roles in invasion and angiogenesis of urothelial carcinomas. Am J Pathol 2007;171:1003-1012.

15 Blumenfeld W, Tucci S, Narayan P: Incidental lymphocytic prostatitis: selective involvement with nonmalignant glands. Am J Surg Pathol 1992;16:975-981.
16 Theyer G, Kramer G, Assmann I, Sherwood E, Preinfalk W, Marberger M, Zechner O, Steiner GE: Phenotypic characterization of infiltrating leukocytes in benign prostatic hyperplasia. Lab Invest 1992;66:96-107.

17 Kawamura K, Komohara Y, Takaishi K, Katabuchi H, Takeya M: Detection of M2 macrophages and colony-stimulating factor 1 expression in serous and mucinous ovarian epithelial tumors. Pathol Int 2009;59:300305 .

18 Mantovani A, Sica A, Sozzani S, Allavena P, Vecchi A, Locati M: The chemokine system in diverse forms of macrophage activation and polarization. Trends Immunol 2004;25: 677-686.

19 Hanada T, Nakagawa M, Emoto A, Nomura T, Nasu N, Nomura Y: Prognostic value of tumor-associated macrophage count in human bladder cancer. Int J Urol 2000;7:263269.

20 Wang XY, Facciponte J, Chen X, Subjeck JR, Repasky EA: Scavenger receptor-A negatively regulates antitumor immunity. Cancer Res 2007;67:4996-5002.

21 Delongchamps NB, de la Roza G, Chandan V, Jones R, Sunheimer R, Threatte G, Jumbelic M, Haas GP: Evaluation of prostatitis in autopsied prostates - is chronic inflammation more associated with benign prostatic hyperplasia or cancer? J Urol 2008;179:17361740.

22 Doble A, Thomas BJ, Furr PM, Walker MM, Harris JR, Witherow RO, Taylor-Robinson D: A search for infectious agents in chronic abacterial prostatitis using ultrasound guided biopsy. Br J Urol 1989;64:297-301. 
23 Nadler RB, Humphrey PA, Smith DS, Catalona WJ, Ratliff TL: Effect of inflammation and benign prostatic hyperplasia on elevated serum prostate specific antigen levels. J Urol 1995; 154:407-413.

24 Nickel JC, Downey J, Young I, Boag S: Asymptomatic inflammation and/or infection in benign prostatic hyperplasia. BJU Int 1999;84:976-981.
25 Robert G, Descazeaud A, Nicolaïew N, Terry S, Sirab N, Vacherot F, Maillé P, Allory Y, de la Taille A: Inflammation in benign prostatic hyperplasia: a 282 patients' immunohistochemical analysis. Prostate 2009;69:17741780 .

26 Begley LA, Kasina S, MacDonald J, Macoska JA: The inflammatory microenvironment of the aging prostate facilitates cellular proliferation and hypertrophy. Cytokine 2008;43: 194-199.

27 Benatar T, Cao MY, Lee Y, Lightfoot J, Feng $\mathrm{N}$, Gu X, Lee V, Jin $\mathrm{H}$, Wang M, Wright JA, Young AH: IL-17E, a proinflammatory cytokine, has antitumor efficacy against several tumor types in vivo. Cancer Immunol Immunother 2010;59:805-817.
28 McDowell KL, Begley LA, Mor-Vaknin N, Markovitz DM, Macoska JA: Leukocytic promotion of prostate cellular proliferation. Prostate 2010;70:377-389.

29 Schioppa T, Moore R, Thompson RG, Rosser EC, Kulbe H, Nedospasov S, Mauri C, Coussens LM, Balkwill FR: B regulatory cells and the tumor-promoting actions of TNF- $\alpha$ during squamous carcinogenesis. Proc Natl Acad Sci USA 2011;108:10662-10667. 